\title{
IMIGRAÇÃO NAS PÁGINAS DO CORREIO BRAZILIENSE
}

\author{
Roberto Rigaud Navega-Costa ${ }^{1}$ \\ Tatiane dos Santos Navega-Costa ${ }^{2}$
}

\begin{abstract}
RESUMO: O Brasil é, sem sombra de dúvidas, um país formado por uma mistura de povos originários e imigrantes, sejam os forçados a vir (como no caso dos homens e mulheres capturados e vendidos a traficantes de escravos nas feitorias no litoral do continente africano), sejam os que optaram por tentar a sorte em um lugar até então selvagem no imaginário dos habitantes do "velho mundo", fugindo da pobreza e da falta de terra e trabalho na Europa, Oriente Médio e Extremo Oriente (principalmente Japão, Coréia e mais recentemente China), sem falar de muitas outras nacionalidades. Este artigo pretendeu encontrar, divulgar e analisar documentos oriundos do jornal Correio Braziliense (que foi impresso entre 1808 e 1822, em Londres) que contivessem referências ao assunto imigração (ou como escrito à época, "immigração"). Para dar conta do objetivo proposto os pesquisadores buscaram no banco de dados da Fundação Biblioteca Nacional, a chamada Biblioteca Nacional Digital Brasil, utilizando-se da ferramenta de busca disponível no site de internet ${ }^{3}$, a Hemeroteca Digital Brasileira, por artigos do Correio Braziliense que tivessem a palavra "immigração". Encontrou-se 5 artigos que continham tal string de busca, que foram anexados ao corpo do texto na forma das Figuras 1 a 5. Pôde-se chegar à conclusão de que havia desde a época da chegada da corte portuguesa ao Brasil, 1808, uma crescente influência do pensamento liberal, que tinha na introdução de mão de obra assalariada, no caso oriunda da Europa, um dos pilares da introdução do modo de produção capitalista na américa colonial.
\end{abstract}

Palavras-chave: Mídia como fonte; Análise Documental; Influência liberal.

\section{LA INMIGRACIÓN EN LAS PÁGINAS DEL MAIL BRAZILIENSE}

RESUMEN: Brasil es, sin duda, un país formado por una mezcla de pueblos originarios y de inmigrantes, ya sean los que vinieron a la fuerza (como en el caso de los hombres y mujeres capturados y vendidos a los traficantes de esclavos en los puestos comerciales de la costa del continente africano), o los que optaron por probar suerte en un lugar hasta entonces salvaje en la imaginación de los habitantes del "viejo mundo", huyendo de la pobreza y la falta de tierra y trabajo en Europa, Oriente Medio y Extremo Oriente (principalmente Japón, Corea y, más recientemente, China), por no hablar de muchas otras nacionalidades. El objetivo de este artículo es encontrar, difundir y analizar documentos del periódico Correio Braziliense (que se imprimió entre 1808 y 1822 en Londres) que contengan referencias al tema de la inmigración (o como se escribía en la época, "inmigração"). Para cumplir el objetivo propuesto, los investigadores buscaron en

\footnotetext{
${ }^{1}$ Doutorando e Mestre no Programa de Pós-Graduação Stricto Sensu - SOCIEDADE, CULTURA E FRONTEIRAS, da Unioeste-Foz do Iguaçu; Bacharel em Filosofia. E-mail: ramosnavega@ gmail.com

${ }^{2}$ Mestranda no Programa de Pós-Graduação Stricto Sensu - SOCIEDADE, CULTURA E FRONTEIRAS, da Unioeste-Foz do Iguaçu; Pedagoga; psicóloga e Psicopedagoga. E-mail: pensandobem.org@ gmail.com ${ }^{3}$ http://memoria.bn.br/hdb/periodico.aspx
} 
la base de datos de la Fundación Biblioteca Nacional, llamada Hemeroteca Digital Brasileña, utilizando la herramienta de búsqueda disponible en el sitio web, Hemeroteca Digital Brasileira, los artículos del Correio Braziliense que tuvieran la palabra "inmigração". Se encontraron 5 artículos que contenían dicha cadena de búsqueda, que se adjuntaron al cuerpo del texto en forma de figuras 1 a 5 . Se puede concluir que desde la llegada de la corte portuguesa a Brasil, 1808, hubo una creciente influencia del pensamiento liberal, que tuvo en la introducción del trabajo asalariado, en este caso procedente de Europa, uno de los pilares de la introducción del modo de producción capitalista en la América colonial.

Palabras-clave: Medios de comunicación como fuente; Análisis documental; Influencia liberal.

\section{INTRODUÇÃO}

O tema da imigração tem tido uma grande relevância no meio acadêmico nos últimos anos no Brasil, principalmente após o terremoto no Haiti (THOMAZ, 2010), em 12 de janeiro de 2010, e a saída de grande contingente de pessoas da Venezuela, desde o agravamento da crise econômica e política naquele país (BARBOSA \& OBREGON, 2018).

No entanto, o Brasil tem um passado referente à imigração que vai desde o tempo colonial, tanto devido ao tráfico e comércio de escravos provenientes do continente africano, quanto com os imigrantes europeus fugindo da pobreza e buscando novas oportunidades no chamado "novo mundo" (SILVA, 2016).

Neste processo, qual foi o papel da imprensa para incentivar ou dificultar a imigração para nosso país? Quais seria os interesses em se fomentar a imigração para o Brasil colonial? Quem ganharia com a presença de trabalhadores livres oriundos da Europa em terras brasileiras?

As questões acima expostas podem ser melhor respondidas à luz das matérias de jornal publicadas pelo periódico Correio Braziliense, que fora publicado entre 1808 e 1822, desde gráficas de Londres, editado por um brasileiro educado em Portugal, mas exilado na Inglaterra (FERREIRA, TURACK \& OLIVEIRA, 2004).

Nesta pesquisa usou-se a análise documental como forma de tratar os dados que foram coletados durante a pesquisa. Partiu-se do princípio de que tais documentos selecionados podem fornecer informações relevantes para o conhecimento científico a respeito do tema das migrações no Brasil. 
Abaixo foram discutidos a metodologia empregada durante a pesquisa, seguido da apresentação dos resultados obtidos pelos pesquisadores durante o processo de coleta de dados, com posterior discussão de tais resultados. Ao fim, o texto traz as considerações de praxe na forma de uma conclusão.

\section{METODOLOGIA}

A metodologia adotada na pesquisa atual, além de ter havido uma pesquisa bibliográfica inicial, segue a classificação seguinte:

- $\quad$ quanto ao objetivo da pesquisa - se trata de uma pesquisa exploratória;

- $\quad$ quanto à natureza da pesquisa - esta é uma pesquisa qualitativa;

- $\quad$ quanto à escolha do objeto de estudo - este é um estudo de caso único;

- $\quad$ quanto à técnica de coleta de dados - esta é uma pesquisa documental;

- quanto à técnica de análise de dados - se trata de uma análise documental.

\section{RESULTADOS}

Após uma pesquisa bibliográfica, procurando subsidiar de informações este trabalho, pôde-se encontrar algumas referências a respeito tanto da utilização do jornal como documento histórico, quanto encontrar dados a respeito do jornal em destaque neste artigo, o Correio Braziliense.

Há muita resistência na utilização de jornais como forma de informação científica, pois muitas vezes tais meios de informação têm um viés muito marcado, tanto político, quanto ideológico, sendo que não se pode, sem incorrer em grave risco de deformação nas informações e nas conclusões, utilizá-los sem se fazer as considerações necessárias para afastar as distorções. No entanto, quando o jornal é não a fonte da análise, mas sim o objeto a ser analisado, este problema fica em segundo plano, pois serão estes fatores que darão mais informações à análise, isto sem contar com o fato de que os jornais fazem uma espécie de fotografia de um dado momento histórico, o que por si só já tem alguma validade. 


\begin{abstract}
Após anos de esquecimento e em condições impróprias à preservação, os jornais foram alçados à categoria de fontes históricas. Essa assunção ao quadro dos interesses dos pesquisadores referenda a renovação temática na pesquisa e emerge do esforço realizado em prol do desenvolvimento científico e tecnológico brasileiro, visando formar recursos humanos para as mais diversas áreas do conhecimento, e nas quais se inclui a educação e a história da educação. (PERIOTTO, 2013, P. 239).
\end{abstract}

Há que se ter em mente que as fontes das quais um cientista se utiliza para construir um conhecimento não são a história, mas sim um registro de acontecimentos que servirão de apoio, de confirmação, de índice, de que algo aconteceu e, em seu conjunto, servirão para compor uma história depois de um tratamento rigoroso por parte do analista (SAVIANI, 2006). Nesta linha de entendimento Celina Murasse (2006) nos lembra que Gilberto Freyre (1900-1987) utilizava matérias de jornal como fonte de suas pesquisas.

[...] a investigação histórica tem de, ao abordar as fontes documentais, ter em conta que elas expressam a síntese de uma multiplicidade de determinações históricas. Expressam as contradições e os conflitos de interlocutores aliados e adversários. Deste modo, o diálogo com um documento histórico deve refletir uma posição de leitura que o toma como síntese consensual do passado. E não como a simples soma das vontades e intervenções. (NORONHA, 1998, p. 33).

Já, se considerar-se o papel histórico de jornais como o Correio Brazieliense, verse-á como sua atuação foi fundamental para o processo de rompimento entre a colônia (Brasil) e a metrópole (Portugal), difundindo novas ideias, argumentando, insuflando, criando rixas, tornando a situação da aristocracia governante insustentável (PERIOTTO, 2013). Foi o efeito causado pelo jornal em estudo nesta pesquisa:

Em $1^{\circ}$ de junho de 1808, Hipólito da Costa inaugurava em Londres o Correio Braziliense, jornal que faria oposição sistemática ao regime absolutista até a independência política em 1822 (...) Escrito e editado em Londres, proibido e contrabandeado ao Brasil, o Correio expressou a emergência de um novo tempo trazido pela consolidação definitiva da sociedade burguesa com a Revolução Francesa. (PERIOTTO, 2013, pp. 246-247).

Não se pode perder de vista o fato de que Londres era a cidade mais importante do mundo àquele momento histórico e que o fato de Portugal e Grã-Bretanha terem laços comerciais estreitos facilitava o contrabando dos jornais para o Brasil, principalmente em 
navios ingleses (TENGARRINHA, 1965). A presença da corte no Rio de Janeiro ajudou a desenvolver a antiga colônia (FERREIRA, TURACK \& OLIVEIRA, 2004), dando impulso à representação de identidades e contrastes entre elas, sendo que no contexto estudado nesta pesquisa "a mídia faz, portanto, muito mais do que apenas refletir as identidades e relações sociais. Seus registros fazem parte do elenco de narrativas e discursos que irão participar da constituição dos sujeitos e definir os contornos das relações sociais" (FERREIRA, TURACK \& OLIVEIRA, 2004, p. 1473).

Ainda nas Palavras de Ferreira, Turack e Oliveira (2004), para se referirem ao jornal que serve de fonte a esta pesquisa, informam que:

\begin{abstract}
(...) em $1^{\circ}$ de junho de 1808, Hipólito José da Costa Furtado de Mendonça, brasileiro que estudou em Coimbra, democrata liberal, maçom, fugitivo da Inquisição portuguesa, imprimia, em Londres, o Correio Braziliense ou Armazém Literario, resultado de uma tentativa de publicar um periódico independente, sem censura prévia (...) o Correio, publicação mensal com suas mais de cem folhas e preço elevado, era opinativo e doutrinário. (FERREIRA, TURACK \& OLIVEIRA, 2004, p. 1475).
\end{abstract}

Abaixo o leitor poderá travar contato com as imagens dos artigos de jornal que puderam ser encontrados e que continham o termo pesquisado, imigração. Estes textos servirão de apoio para as considerações que serão feitas na próxima seção desta pesquisa, a parte dedicada à discussão dos resultados.

A Figura 1 traz o artigo "Commércio e Artes", de 1811, onde pela primeira vez aparece a palavra "immigração". Recomenda-se que o leitor faça uma leitura atenta dos textos, começando por este citado. A Figura 2, sob o título "Miscellanea" (1815), traz a segunda referência ao termo estudado. Já a Figura 3 é ainda mais direta, pois traz o título "Immigração no Brazil" (1816), lidando diretamente com o assunto de interesse. “População. Nova Capital no Brazil” (1816) é o título da matéria de jornal apresentada na Figura 4 e a última matéria que veio a citar imigração no jornal Correio Braziliense, mostrada na Figura 5, lidou com o tema na forma de "Miscellanea" (1821) novamente. 
Quando se observa a introducçaõ da utilissima cultura do algodaõ no Brazil; o principio da plantaçaõ das batatas na Irlanda, e outras partes da Europa, naó póde deixar de conhecer-se, quam importante serîa ao Brazil o favorecer a immigraçaõ de agricultores instruidos de differentes partes da Europa que soubessem escolher os terrenos para as diversas plantas, e as plantas que convem aos terremos de varias qualidades, que existem na vasta extençaõ daquelle territorio, aonde ha chaõs, e climas de incalculavel variedade.

Fonte: Correio Braziliense (Londres, ING) - 1811 - Edição 00006 - p. 229. 
por outros termos, a prohibiçaô da importaçaర̃ de escravos d'Africa para o Brazil.

A. consequencia desta medida será logo o augmento do preço dos escravos, que ha no Brazil; e por isso a maior carestia da maõ d'obra, e augmento de valor nos productos. He ésta difficuldade, que he necessario obviar ao principio; e para isto naô vemos senaó dous methodoz. Um he a intro. ducçaő das maquinas, em todos os trabalhos aonde ellas pó. dem supprir o emprego de homens; outro he a immigraçaó de gente daquellas partes da Europa, aonde a pupalaçaõ tem pouco enprego.

A Inglaterra, a França, e os Estados Unidos abundam em Engenheiros-Civis e maquinistas; exaqui, pois, uma classe de geite, que se faz, nesta occasiaoo, summamente importante no Brazil ; e que deve servir para fomentar o primeiro methodo, que temos proposto; assim como tambem a introducçaó das novas invençoens de arados, e outros instrumentos de agricultura, que diminûam o uso da enchada, taố commum no Brazil, pelo máo systcma das roças, e em que se empregam mais braços do que seria necessario, adoptando-se os instrumentos de agricultura, que diariamente se estaõ inventando; na Europa,

0 augmento de braços para o trabalho, com emigrados da Europa, nos parece materia de pouca difficuldade; ainda que julgamos será de consideravel despeza para o Estado; mas ésta ficará ao depois amplamente compensada, pela permanente riqueza, que tal importaçaô deve trazer ao Brazil : por quanto muitos seculos se passaraó, antes que o vasto territorio daquelle Estado possa ter populaçaó demasiada.

Fonte: Correio Braziliense (Londres, ING) - 1815 - Edição 00015 - p. 737. 


\section{Immigraçaõ no Brazil.}

O Brazil he agora sem duvida a mais importante parte da monarchia Portugueza, o ao mesmo tempo aquella, que tem

- menor populaçaô. Este ponto he demasiado importante, para que deixemos de tornar a fallar nelle uma rez mais.

Duascousas desejamos aqui recommendar : uma, a introduç̧a de emigradọs, em geral : outra a edificaçaõ de uma cidade nó interior; que renha pelo tempo adiante a servir de capital no Brazil.

E quanto á primeira; contôm lembrar o exemplo de outros paizes; para desabusaras pessoas, que ainda hesitam, sobre as utilidades do expediente de favbrerer a immigraçaõ, em um paiz, aonde a populaçaó be proporçionalmente taŏ diminuta; as sciencias e as artes taõ atrazadas.

A bajxo rerá o Leitor, no artigo dos Estados Unidos, alguma noticia do rapido augmento de populaçaõ, industria, e riqueza, que tem procurado áquelle paîz o prudente conselho defavorecer, por todos os modos possiveis, a introduçaó dos estrangeiros.

Perém naó he sómente a practica moderna dos Estados Unidos, que temos a favor desta politica ; inumeraveis outros paizes tem florecido, adoptando a mesma maxima de introduzir populaçaó estrantgeira.

O prodigioso melhoramento na agricultura, nas artes, na ediflcaçaõ das cidades, villas e lugares; a aflluencia de povo, e.em fim a industria de todo o genero, que se, observava nos Paizes baixos, fó mui principalmente devida ás guerras civis,

Fonte: Correio Braziliense (Londres, ING) - 1816 - Edição 00016 - p. 628. 
Reflexoens sobre as Novidades deste Mez.

REYMO ENIDO DE PORTUGAL DO BRAZIL E DO\$

A LGA RVES.

\section{Populaçaõ. Nova Capital no Brasil.}

Indicamos no nosso $\mathrm{N}$ • passado algumas breves noçoens; sobre a necessidade de promover a immigraçaó de estrangeiros no Brazil ; e fomentar os estabelecimentos de terra dentro, edificando uma nova cidade, para ser a capital e sede do Governo do Brazil. O Leitor nos permittirá ainda outravez o fallarmos desta materia, que julgamos de grandissima consequencia, para a prosperidade daquelle paiz.

O systema, que recommendamos, de favorecer a immigraçaő de estrangeiros, tem sempre em vista o facilitar-lhes todos on meios de so estabelecerem no interior do paiz; deixando os

Fonte: Correio Braziliense (Londres, ING) - 1816 - Edição 00017 - p. 95. 
Revista eletrônica de Filosofia

\section{Alamedas}

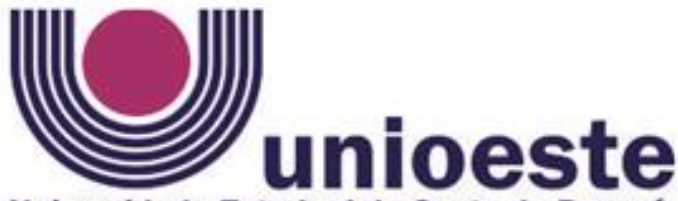

Universidade Estadual do Oeste do Paraná

Contra os seus interesses; porque os Europeos estabelecidos no Brazil, com suas familias, seus cabedaes, seu modo de vida, bem Brazileiros saô, e tam bóns como muitos dos nascidos no paiz. Teraõ talvez alguma maior predilecçaõ pela provincia em que nasceram ; isso tem elles direito a ter, está tam longe de serlhes nodoa, que lhes serve de louvor, e nem essa parcialidade os faz menos bons cidadaõs, naổ mais do que o Paráense no Rio-deJaneiro, que mostre afferro pelas margens do Amazonas, ou um Transmontano no Alemtejo, que se deleite em louvar os outeiros em que foi criado.

Seja a disputa excitada pelo Governador Rego, ou por quem quer que for, se os Pernambucanos derem um passo que sêja, em perpetuar a distineçaõ entre Portuguez e Braziliense; mais, se a Juncta Provisoria de Governo naõ cuidar positivamente em abolir e extinguir esse germen de divisaõ, tam culpada a teremos entaõ, como temos agóra o mesmo Rego.

He do primeiro interesse para o Brazil fomentar a immigraçaõ para ali dos Portuguezes, e se os espantárem com pueris distincçoens, os que para isso contribuirem saõ tam inimigos dos Pernambucanos como se mostrou Rego.

Fonte: Correio Braziliense (Londres, ING) - 1821 - Edição 00027 - p. 537.

\section{DISCUSSÃO}

Como o leitor poderá verificar, as figuras foram organizadas de forma cronológica, no intuito de facilitar a leitura, o entendimento, o desenrolar dos fatos e a análise documental que se inicia neste momento, sendo que a primeira consideração que se pode fazer é se este corpus é suficientemente bom para possibilitar a análise documental. Em relação a este quesito, pode-se argumentar que como os documentos separados são os únicos que contêm o termo pesquisado no universo de textos possíveis, eles têm de ser adequados, já que formam um subconjunto coeso dentro do total de possibilidades estudáveis. 
Quanto à credibilidade, uma vez que os textos foram obtidos em um banco de dados estatal, que tem o intuito de preservar e divulgar tais informações ao público, sendo uma instituição reconhecida como academicamente relevante, é razoável considerar que os documentos a serem analisados têm credibilidade transferida por sua fonte de divulgação.

Já se se questionar a representatividade dos documentos, pode-se inferir que o jornal que deu origem aos mesmos foi um dos dois jornais que circulavam no Brasil da época, sendo o Correio Braziliense um periódico não oficial, não aprovado pelo governo à época estabelecido, sendo representativo pela quase exclusividade e pela posição editorial única em seu tempo.

Quanto à fidelidade das informações reportadas, lembre-se de que este era uma publicação particular, contendo a opinião dos editores. Sendo assim, o editor apenas escrevia o que aprovava e o que condizia com sua ideologia particular ou de seu grupo de interesses. Desta forma, se se estudar o texto em si e suas repercussões, é irrelevante sua fidelidade externa aos fatos narrados.

Quanto ao sentido da mensagem, é necessário examinar-se cada um dos cinco documentos destacados acima neste texto, para que se possa analisar mais cuidadosamente e para se poder ter uma imagem a respeito tanto da mensagem, quanto da intensão por trás dela. Para tal, se utilizará de alguns critérios de análise, como: contexto; autor; autenticidade e a confiabilidade; natureza do texto; conceitos-chave e a lógica interna do texto.

Iniciando a análise pelo contexto de produção dos documentos escolhidos, podese utilizar de informações já prestadas acima, que citaram o fato de o jornal ter sido editado por um brasileiro, que era impresso em Londres, que iniciou suas atividades em 1808 (ano em que a corte portuguesa chegou ao Brasil, fugindo das tropas de Napoleão Bonaparte (GOMES, 2014)) e encerrou as atividades em 1822 (quando parte da corte portuguesa já voltara à metrópole (GOMES, 2014)). O que se pode supor é que pode ter havido uma convergência de interesses na edição deste jornal.

A Inglaterra se encontrava em plena expansão industrial, quando buscava mercados fornecedores (de matérias-primas) e consumidores (para seus produtos industrializados) (HOBSBAWM, 2015), o que fazia do Brasil um local perfeito para reunir à sua zona de influência comercial. Um jornal em português, introduzindo um 
pensamento modernizante, industrial e liberal, aos modelos ingleses, poderia criar uma classe dirigente no Brasil (pelo menos em quem pudesse ler) que poderia ser vantajosa a médio e a longo prazos para o império britânico.

Ao prestar-se atenção ao autor, pode-se pensar que apenas uma pessoa não daria conta facilmente da grande quantidade de texto editado, pois o Correio Braziliense era uma edição muito densa, contendo muitas páginas. Isto abre margem para que se possa inferir que havia um grupo de escritores a serviço de Hipólito José (ou de algum personagem ou grupo oculto). Isto levanta um outro ponto: quem financiava o periódico? Imprimir um jornal de mais de cem folhas, mensal, dirigido a um país distante, contando com um governo hostil à publicação, com um público potencial consideravelmente baixo (devido ao analfabetismo (FLORES, 2017)) seria um risco e careceria de um investimento considerável. Quem pagou por isto? Aparentemente, há uma grande chance de os textos deste jornal servirem a interesses políticos ligados ao local de origem da mensagem, o que indicaria um forte viés ideológico, uma marcada presença do liberalismo Inglês.

A autenticidade e a confiabilidade do documento, no que se refere ao seu texto, está diretamente relacionada à relação entre o autor e o que ele insere no texto (SÁSILVA, ALMEIDA \& GUINDANI, 2009). No caso em estudo, o autor não estava no Brasil à época das publicações, não sendo testemunha dos acontecimentos, sendo apenas comentarista do que recebeu como informação e trabalhando como agente opinativo e ideológico.

A distância geográfica e temporal entre a saída da informação do Brasil, a sua recepção em Londres, a criação do texto comentando algum fato, a publicação do mesmo no jornal e a chegada ao Brasil do periódico dão ao processo um ar de demora. No entanto, se se considerar a tecnologia da época, pode ser que o público leitor não tivesse a mesma impressão que se tem hoje ao se olhar retrospectivamente para o processo como um todo.

Outras possibilidades de análise seriam se o autor "reportou as falas de alguma outra pessoa? Ele poderia estar enganado? Ele estava em posição de fazer esta ou aquela observação, de estabelecer tal julgamento?" (SÁ-SILVA, ALMEIDA \& GUINDANI, 2009, pp. 9-10). Recebendo informações de segunda mão, seria extremamente difícil para Hipólito José (ou outro autor anônimo) ser fiel à informação por ele recebida (principalmente por esta poder ter sido enviesada pelo emissor ou pelo mensageiro), dando pouca margem a ele para estabelecer um julgamento adequado à cada situação, o 
que reserva o espaço à sua opinião como sendo o ponto focal de análise, já que esta mostraria sua posição ideológica frente aos acontecimentos.

Se analisar-se a natureza do texto estudado nesta pesquisa, pode-se constatar que há uma aparência de que se trata de um texto jornalístico, principalmente quando se refere ao governo de Pernambuco e sua resistência em aceitar portugueses em seu território (FIGURA 5). No entanto, se levarmos em conta o que foi considerado acima, a respeito do atraso nas informações, o texto passa a ser mais próximo de um opinativo, no qual, com base em poucos dados, tem-se a oportunidade de tentar influenciar as opiniões dos leitores.

Para tentar entender os conceitos-chave e a lógica interna dos textos estudados, tem-se que "avaliar sua importância e seu sentido, segundo o contexto preciso em que eles são empregados. Finalmente, é útil examinar a lógica interna, o esquema ou o plano do texto: Como um argumento se desenvolveu? Quais são as partes principais da argumentação?" (SÁ-SILVA, ALMEIDA \& GUINDANI, 2009, p. 10).

Desta forma a Figura 1 apresenta a introdução da ideia de imigração europeia. Aproveitando-se da notícia da introdução do cultivo de algodão no Brasil, o autor faz um paralelo entre o sucesso do plantio de batatas na Europa, na tentativa de argumentar a favor de uma maior qualidade do europeu na atividade agrícola. Então, abre espaço para introduzir a ideia de que se deveria "favorecer" a imigração de agricultores instruídos.

O curioso, neste caso, é que o autor vê o Brasil como tendo vocação apenas agrícola. Por que não incentivar a indústria no Brasil? Será que é porque a ideia é ter o país como fornecedor de matérias-primas, não como concorrente das indústrias inglesas? Atente-se ao fato de haver um elogio que traz a mesma ideia da carta de caminha em relação ao Brasil, onde há o acréscimo de que faltaria apenas o europeu para escolher as melhores condições de plantio.

Na Figura 2 pode-se encontrar um texto mais complexo. Há o final de uma informação a respeito da possibilidade da proibição do tráfico negreiro, do continente africano para o Brasil. Seguindo uma análise econômica, o autor liga a primeira ideia às suas consequências, como o aumento do preço dos escravos que já estivessem no país quando da proibição, que encareceria o custo da mão de obra, o que acarretaria em uma inflação maior. 
Como meio de resolver o problema há a sugestão de se introduzir maquinário e se incentivar a imigração europeia ao Brasil. Os fornecedores de máquinas e de engenheiros poderiam ser os norte-americanos, os ingleses e os franceses. Há de se lembrar que os norte-americanos ainda estavam se industrializando e acabavam de sair de uma guerra de independência contra a Inglaterra há poucas décadas (JENKINS, 2019). Ao mesmo tempo, a corte portuguesa acabara de fugir para o Brasil na tentativa de evitar o exército francês que ocupara Portugal. Assim, é altamente improvável que o governo instalado no Rio de Janeiro fosse aceitar um acordo com quem estava a usurpar seus poderes de soberania. A alternativa seria a Inglaterra, o país cujo governo ajudou na fuga para o Brasil (GOMES, 2014), que tinha iniciado a Revolução Industrial (HOBSBAWM, 2015) e que abrigava o autor e seu jornal. Desta forma, o autor do texto finge neutralidade, mas parece sugerir a abertura de um mercado para os produtos e os técnicos ingleses.

Outro ponto levantado é o incentivo à imigração europeia ao Brasil, unindo à ideia da associação de compra de equipamentos agrícolas que poupariam o uso de braços no campo. O patrocinador destas compras seria o governo instalado no Rio de Janeiro, "ainda que julgamos será de considerável despesa para o Estado", lembrando que o investimento compensaria e traria riqueza, além do fato de que o brasil levaria séculos para ser totalmente habitado (outro argumento em prol da imigração).

A Figura 3 traz um texto que é mais objetivo em relação às suas intenções de argumentar e convencer o leitor em relativamente à necessidade e às vantagens de se adotar no Brasil um processo de imigração, tanto que o título da matéria é "Immigração no Brazil". No início o autor lembra de dois fatos, o primeiro é o fato de o Brasil ser a parte mais importante da monarquia portuguesa, já a segunda é o fato de a população do Brasil ser muito pequena em relação ao seu território.

Logo após há a repetição do assunto imigração e a introdução de um novo tópico, o da necessidade de se criar uma nova capital para o Brasil no interior. Aparentemente o autor tem a tendência de introduzir temas exóticos ao principal do texto, para trabalhá-los mais tarde. Foi assim com a imigração, apenas uma ideia, que agora ganha um texto próprio.

O autor gasta um parágrafo para chamar a atenção de volta ao tema original, para no quarto parágrafo utilizar os Estados Unidos como exemplo de imigração bem sucedida. No quinto parágrafo o autor alude a outros exemplos bem sucedidos de 
imigração europeia, no entanto não há a menção de nenhum outro país. Acabando o texto a lidar com questões históricas europeias irrelevantes neste estudo.

Na Figura 4 encontra-se a retomada do tema imigração aliada à necessidade de uma nova capital para o Brasil. Como mencionado acima, o autor introduz um tema e o trabalha em outra edição, como pode ser visto agora. A recorrência do tema parece ser uma espécie de propaganda da ideia de imigração, tanta é a insistência apresentada, como se fosse uma matéria jornalística encomendada.

A Figura 5 traz novamente o nome de "Miscellanea", o que dá uma ideia de menor importância ao texto. Esta foi a última menção ao tema imigração que foi citada no Correio Braziliense, que viria acabar suas atividades no ano seguinte, 1822. É como se o fato de a família real portuguesa ter retornado para Portugal diminuísse a necessidade do jornal existir.

Este texto foi o único que citou uma notícia da colônia dentre os cinco que falavam sobre imigração. Quando fala da atitude do governador de Pernambuco em relação aos imigrantes portugueses (DO REGO ABRANCHES, 1822), parece que apenas usa o fato para defender novamente a imigração, mas agora de forma mais fraca que antes.

O que os pesquisadores puderam perceber é que houve, com a mudança da corte portuguesa para o Rio de Janeiro, a oportunidade de tentar fomentar ideias liberais, de incentivar a imigração de europeus ao Brasil, de tentar criar as condições para a troca da mão de obra escrava para uma assalariada, de abrir um mercado para os produtos industrializados oriundos da Inglaterra, somando-se a isto a adoção da mão de obra especializada dos engenheiros britânicos. Neste panorama, quem financiou o jornal Correio Braziliense parece ter trabalhado ideologicamente para tornar o Brasil um país capitalista e liberal, possibilidade que merece maiores estudos.

\section{CONCLUSÃO}

Chegou-se ao final da pesquisa que teve como intuito a análise documental do periódico Correio Braziliense, focando-se em cinco fontes documentais específicas, todas abordando direta ou indiretamente o tema da imigração, que no caso se tratou de defender a imigração para o Brasil de europeus. 
A análise documental foi feita na seção anterior e, para o tamanho e limitações desta edição, se deu de forma satisfatória na visão dos autores. Foram apresentados dados e parâmetros utilizados para a avaliação destes mesmos dados, isto após uma pesquisa bibliográfica inicial, dando ao leitor a oportunidade de entender a sequência de ideias e a metodologia que regeram a pesquisa.

O tema ainda é muito atual e a análise documental pode ainda contribuir muito para as pesquisas com fontes jornalísticas, como no exemplo do Correio Braziliense. No entanto, tal tema e abordagem merecem um espaço mais amplo e uma dedicação maior, com o intuito de acrescentar mais fontes e ampliar o escopo da pesquisa.

O que se pode acrescentar é a sugestão de que outros autores possam utilizar este trabalho para refletirem a respeito da validade do método de se trabalhar com documento e de os analisar utilizando-se dos parâmetros apresentados aqui. Cada um destes jornais é uma espécie de tesouro, uma espécie de cápsula do tempo, que merece e precisa ser aberta e trazida à luz da ciência a partir de um processo analítico próprio. Espera-se que isto ocorra em breve.

\section{REFERÊNCIAS BIBLIOGRÁFICAS}

BARBOSA, Carolina Coelho; OBREGON, Marcelo Fernando Quiroga. Venezuela para além das fronteiras: análise do impacto da crise venezuelana na população e na saúde pública de Roraima. Revista Derecho y Cambio Social, n. 54, 2018.

COMMÉRCIO e Artes. Correio Braziliense. 1811, Edição 00006, p. 229. Disponível em: $<$ http://memoria.bn.br/DocReader/docreader.aspx ?bib=700142x\&pesq=immigra\%C3\% A7\%C3\%A3o\&pagfis=3344>. Acesso em: 23 ago. 2021.

DO REGO ABRANCHES, Antonio Manoel. Memória justificativa sobre a conducta do Marechal de Campo Luiz do Rego Barreto: durante o tempo em que foi Governador de Pernambuco e Presidente da Junta Constitucional do Governo da mesma província, offerecida a'nação portugueza. Editora Universitária da Universidade Federal de Pernambuco, 1822.

FERREIRA, Lucia M. A.; TURACK, Cynthia Fevereiro; OLIVEIRA, Monalisa Pavonne. (Des)Estabilizando Identidades: As Mulheres na Imprensa do Início do Século XIX. ANAIS DA XX JORNADA - GELNE - JOÃO PESSOA-PB, 2004.

FLORES, Sharon Rigazzo. A democratização do ensino superior no Brasil, uma breve história: da colônia a república. Revista internacional de educação superior, v. 3, n. 2, p. 401-416, 2017. 
GOMES, Laurentino. 1808: como uma rainha louca, um príncipe medroso e uma corte corrupta enganaram Napoleão e mudaram a história de Portugal e do Brasil. Globo Livros, 2014.

HOBSBAWM, Eric. A era das revoluções: 1789-1848. Editora Paz e Terra, 2015.

IMMIGRAÇÃO no Brazil. Correio Braziliense. 1816, Edição 00016, p. 628. Disponível em: <http://memoria.bn.br/DocReader/docreader.aspx?bib=700142x\&pesq=immigra\% C3\%A7\%C3\%A3o\&pagfis=12312>. Acesso em: 23 ago. 2021.

JENKINS, Philip. Breve historia de Estados Unidos. Quinta edición. Alianza Editorial, 2019.

MISCELLANEA. Correio Braziliense. 1815, Edição 00015, p. 737. Disponível em: $<$ http://memoria.bn.br/DocReader/docreader.aspx ?bib=700142x\&pesq=immigra\%C3\% A7\%C3\%A3o\&pagfis=11659>. Acesso em: 23 ago. 2021.

MISCELLANEA. Correio Braziliense. 1821, Edição 00027, p. 537. Disponível em: $<$ http://memoria.bn.br/DocReader/docreader.aspx ?bib=700142x\&pesq=immigra\%C3\% A7\%C3\%A3o\&pagfis=20613>. Acesso em: 23 ago. 2021.

MURASSE, Celina M. O Auxiliador da Indústria Nacional e a educação. In: CONGRESSO BRASI-LEIRO DE HISTÓRIA DA EDUCAÇÃO, 4., 2006, Goiânia, GO. Anais... Goiânia: CBHE, 2006.

NORONHA, Olinda Maria. História da Educação: sobre a origem do pensamento utilitarista no ensino superior brasileiro. Campinas, SP: Alínea, 1988.

PERIOTTO, M. R. A imprensa brasileira nos oitocentos e a história da educação: Hipólito da Costa e o Correio Braziliense. Série-Estudos - Periódico do Programa de PósGraduação em Educação da UCDB, n. 36, 17 dez. 2013.

POPULAÇÃO. Nova Capital no Brazil. Correio Braziliense. 1816, Edição 00017, p. 95. Disponível em: <http://memoria.bn.br/DocReader/docreader.aspx?bib=700142x\&pesq= immigra\%C3\%A7\%C3\%A3o\&pagfis=12454> . Acesso em: 23 ago. 2021.

SAVIANI. Dermeval. Breves considerações sobre fontes para a história da educação. Revista Histedbr. On-line, n. 22, agosto, 2006.

SILVA, Elizete. Europeus e indígenas na América portuguesa. E-Revista de Estudos Interculturais do CEI, v. 4, 2016.

TENGARRINHA, José. História da Imprensa Periódica Portuguesa. Lisboa: Portugália Editora, 1965. 
Revista eletrônica de

Filosofia

Alamedas

THOMAZ, Omar Ribeiro. O terremoto no Haiti, o mundo dos brancos e o Lougawou. Novos estudos CEBRAP, p. 23-39, 2010. 